\title{
REFLEXÕES SOBRE QUESTÕES ÉTNICO-RACIAIS DOS JOVENS NEGROS DO MUNICÍPIO DE CAMPOS DOS GOYTACAZES
}

\author{
Edson R. Andrade', Paula Márcia S. Sousa ${ }^{1^{*}}$, Luma S. Moté2, Laura R. da S. Siqueira ${ }^{2}$ \& \\ Miguel A. Ribeiro ${ }^{2}$
}

\begin{abstract}
RESUMO
ANDRADE, E.R.; SOUSA, P.M.S.; MOTÉ, L.S.; SIQUEIRA, L.R.S.; RIBEIRO, M.A. Reflexões sobre questões étnico-raciais dos jovens negros do município de Campos dos Goytacazes.Perspectivas Online: Humanas \& Sociais Aplicadas,v.9,n.26,p.98-112,2019.
\end{abstract}

A presente pesquisa sobre as percepções étnico-raciais da juventude negra de Campos dos Goytacazes, tem a perspectiva de constribuir para concepções de novos horizontes pessoais e sociais no que diz respeito ao racismo velado ou explícito ainda existente na sociedade brasileira. $\mathrm{O}$ trabalho tem como objetivo geral analisar as percepções fenomenológica da juventude negra de Campos dos Goytacazes-RJ sobre a sua autoimagem e autoestima. A pesquisa te o compromisso de dar voz à juventude negra de Campos dos Goytacazes, discutir tabus, perceber a existência de preconceitos velados, possibilitando uma abertura para o diálogo dentro do contexto social e acadêmico sobre questões étnico-raciais. Os primerios resultados da pesquisa revelam que a discriminação contribui diretamente para o aumento da segregação social; torna difícil o enfrentamento de realidades; evita questionamentos; e afasta, muitas vezes, de forma sutil tentativas de inclusão social. Os estigmas normalmente são reunidos em três grandes grupos, conforme essa linha teórica: as deformidades físicas; as culpas de caráter individual (desonestidade, entre outros); e os estigmas tribais de raça, nação, religião, por exemplo. As pessoas ditas como normais, tendem a se agrupar e a estabelecer padrões de comportamentos que serão impostos ao coletivo, que acabam aceitando e tornando esses padrões como normas de convivência dentro daquele grupo. Aos que não se enquadrarem dentro dos padrões estabelecidos pelo grupo serão estigmatizados. Destarte acredita-se que o convívio obrigatório das pessoas estigmatizadas com as ditas "normais", principalmente quando o grupo a que pertencem não podem excluí-lo, podem levar a baixa estima e por vezes a assumir e concordar com a condição de inferior, levando a depressão ou a outros estados patológicos. Também está sendo observado que o preconceito é passado de geração em geração, sendo uma construção social. Por isso, se ele é construído também pode ser desconstruído.

Palavras-chave: Rede Social; Estigma; Jovens Negros; Psicologia. 


\begin{abstract}
This research on the ethnic-racial perceptions of black youth in Campos dos Goytacazes has the perspective of contributing to the conceptions of new personal and social horizons regarding the veiled or explicit racism still existing in Brazilian society. This paper aims to analyze the phenomenological perceptions of black youth from Campos dos Goytacazes-RJ about their self-image and self-esteem. The research is committed to giving voice to the black youth from Campos dos Goytacazes, discussing taboos, perceiving the existence of veiled prejudices, by allowing an opening for dialogue within the social and academic context on ethnic-racial issues. The first results of the research reveal that discrimination contributes directly to the increase of social segregation; makes it difficult to confront realities; avoids questions; and often subtly dispels attempts at social inclusion. Stigmas are usually grouped into three large categories

along this theoretical line: physical deformities; individual character faults (dishonesty, among others); and the tribal stigmas of race, nation, and religion, for example. People said to be normal tend to group together and set patterns of behaviors that will be imposed upon the collective, who eventually accept and make these standards into coexistence norms within that group. Those who do not meet the standards set by the group will be stigmatized. Thus, it is believed that the obligatory coexistence between stigmatized people and the so-called "normal", especially when the group which they belong to cannot exclude them, may lead to low self-esteem and sometimes to assume and agree with the condition of being inferior, leading to depression or other pathological conditions. It has also been observed that prejudice is passed down from generation to generation, being a social construction. Therefore, if it is constructed, it can also be deconstructed.
\end{abstract}

Keywords: Social Network; Stigma; Black Youth; Psychology.

\footnotetext{
${ }^{1}$ Pesquisadores do Laboratório de Estudos Fenomenológicos - NEFE/ISECENSA, Institutos Superiores de Ensino do CENSA - ISECENSA - Rua Salvador Correa, 139, Centro, Campos dos Goytacazes, RJ, CEP: 28035-310, Brasil.

${ }^{3}$ Alunos(as) do Programa Voluntário de Iniciação Científica-PROVIC Institutos Superiores de Ensino do CENSA ISECENSA - Rua Salvador Correa, 139, Centro, Campos dos Goytacazes, RJ, CEP: 28035-310, Brasil.

(*) e-mail: paulamseabra@yahoo.com.br

Data de recebimento: 23/10/2019. Aceito para publicação: 06/11/11
}

Persp. Online: hum \& sociais aplicada., Campos dos Goytacazes, 26 (9) 98-112- 2019 seer.perspectivasonline.com.br 


\section{INTRODUÇÃO}

A vivência em uma sociedade preconceituosa, que tem o racismo como resistente marca e a discriminação como característica, coloca o indivíduo na posição de questionador acerca das percepções e sentimentos daqueles sujeitos que os enfrentam cotidianamente.

Ferreira e Pinto (2014) entendem que o racismo, em virtude de características fenotípicas como a cor da pele, é a marca principal para justificar o tratamento diferenciado para as pessoas que possuem o fenótipo da raça negra. Ser negro e jovem no Brasil é considerado um enorme desafio; lutar contra a segregação, a taxação de postura, a diminuição de seus direitos, passa a ser uma das inúmeras lutas por mostrar a sua presença na sociedade, também como pessoa humana e participante ativo deste meio.

Quando se fala de racismo e preconceito, Cunha (2015) destaca estes conceitos como interligados, sendo o racismo um tipo de preconceito, racial ou étnico, quer dizer, uma idéia pejorativa e preconcebida a respeito da etnia ou raça.

Historicamente, no Brasil, como pontuam Schucman et al. (2017), a raça é responsável pela hierarquia e por distinguir grupos assinalados pelo fenótipo. As características físicas como os traços fortes, cor do cabelo e da pele, são condições empregadas para discriminar e categorizar grupos raciais, principalmente entre negros e brancos.

As desigualdades, oriundas da discriminação social, apresentam três pontos principais em seu fundamento segundo pesquisas a cerca das relações raciais no Brasil, são eles: a inferioridade locacional, a inferioridade educacional e por fim a inferioridade ocupacional. Essa tríade ainda é responsável pela diferença atual de remuneração por raça (BARROS; MENDONÇA, 1996). Silvério (2003) critica que no território nacional, o rendimento, a saúde e a educação sofrem ação direta e forte da gritante desigualdade social, e isso não é reconhecido. Infelizmente, ainda hoje a questão racial insiste em ser item de decisão, quando se contrata a partir de traços físicos do sujeito, gerando uma discriminação individual ou coletiva (SILVÉRIO, 2004).

Racismo, na perspectiva da Declaração Sobre Raça e os Preconceitos Raciais (1978 apud Cunha, 2015, p. 10):

é, na sua essência, uma doutrina sustentada pela ideia de que uma raça é superior à outra e que, assim o sendo, resulta na marginalização, segregação e separação de uma raça em detrimento de outra, por declarar-se superior. Assim, o referido autor pontua a existência de vários tipos de racismo, entre eles se destacam: racismo individual, institucional, cultural, primário, comunitarista ou diferencialista, além do racismo ecológico ou ambiental e o racismo velado.

O racismo é o responsável por edificar fantasmas, conceitos e hábitos discriminatórios, apenas por colocar em evidência um determinado grupamento (POLIAKOV et al., 1977). Raça e racismo, no Brasil, ainda são temas encobertos, com isso, o jeito de falar é por meio das diferenças de classes, da marginalização daqueles que tem menos e por meio do falar não falando (SCHUCMAN et al., 2017). Ainda segundo estes autores, o desequilíbrio simbólico e utilitário são peças fundamentais na edificação da raça e do preconceito por parte da população brasileira.

Persp. Online: hum \& sociais aplicada., Campos dos Goytacazes, 26 (9) 98-112- 2019 
Nogueira (1985 apud PINTO; FERREIRA, 2014, p. 260) destaca que "o preconceito pode ser identificado em duas modalidades: o preconceito de marca e o preconceito de origem". Para esse autor o preconceito de marca está associado a discriminação da cor e em relação às outras características físicas, tomando como pretexto as características físicas, as aparênicas, as ações, a maneira de falar, o que acarretará em preferências por uma raça. Já o preconceito de origem determina que a pessoa necessita somente ser descendente de um determinado grupo étnico e assim sofrer as consequências da discriminação racial, sofrendo com as formas de exclusão social (PINTO; FERREIRA, 2014).

O racismo se prende a estereótipos, concedendo um significado de inferioridade e maldade, não identificando suas distinções. Desta forma, o negro sempre recebe um "selo" do estigma, tendo sua tonalidade de pele fundamento essencial para essa estigmatização. As questões fenotípicas do negro, trazendo foco principal para sua cor de pele, aproximam-se da questão racial que Erving Goffman, chamou de "teoria do estigma" (RAMOS, 2009).

$$
\text { Segundo Souza (2005 apud RAMOS, 2009, p. 05): }
$$

o branqueamento é um dos desdobramentos do racismo, bastante mascarado no
Brasil. Em sua pesquisa, apenas $28,1 \%$ dos negros participantes, admitiram terem
visto ou sofrido discriminação. Tais resultados remetem à pesquisa citada pelo autor
feita em 1996 pelo Instituto Datafolha em que $89 \%$ dos brasileiros afirmaram a
existência do racismo no Brasil, porém, apenas $10 \%$ admitiram ter uma postura
racista. Nesse estudo, Souza conclui que o preconceito no Brasil está relacionado à
cor ou à raça, isto é, não apenas à questão de classe. Sendo assim, a discriminação
com o negro é uma questão cultural e sua imagem é, portanto, estereotipada e
estigmatizada.

Cabe salientar que Madeira e Gomes (2018) sustentam que o racismo pode ser entendido por meio das relações de poder, que são estabelecidas no meio das instituições sociais, sendo que para haver uma superação dessa compreenção é necessário também haver uma reforma destas. Por isso, a necessidade de reflexões e análises críticas sobre as implicações e relações entre as raças pós-abolição e a permanência do racismo na sociedade e nas relações.

Por fim, Madeira e Gomes (2018, p. 464) afirmam que a população negra do Brasil:

\begin{abstract}
tem sido subjugada, violentada e criminalizada desde a escravidão para saciar os interesses sociais e econômicos das classes ricas. Assim, a propagação do discurso preconceituoso e discriminatório alicerça a narrativa para desqualificar a cidadania afrodescendente. $O$ discurso da acomodação, que afirmava serem os negros acomodados com sua situação e condição, os considerava vítimas com defeitos. Por isso, os negros eram tratados como infantilizados e deles retirada sua humanidade. Desta forma, as desvantagens que se acumularam foram associadas à cor da pele, de um povo dado à escravidão e mal ajustado.
\end{abstract}

No Brasil, historicamente as perspectivas e atitudes sobre os diferentes segmentos étnico-raciais da população têm se traduzido em arranjos e políticas sociais que limitam oportunidades, formas de tratamento e expectativas de vida. Essas limitações conduzem a "população negra, que corresponde à soma de pretos e pardos na classificação do IBGE e constitui aproximadamente $45 \%$ dos brasileiros, às condições de vida desiguais quando comparada à população branca" (MARTINS; COLOSSO, 2013, p. 119).

Visto que o racismo assume um papel psicossocial, a psicologia ocupa seu lugar em tal discussão quando propõe uma posição de defrontamento contra o racismo, na intenção de

Persp. Online: hum \& sociais aplicada., Campos dos Goytacazes, 26 (9) 98-112- 2019

seer.perspectivasonline.com.br 
proporcionar ao grupo social segregado um equilíbrio psíquico. A psicologia virá conjuntamente como fonte de auxílio ao grupo estudado e sobretudo aos negros em geral, na construção ou reconhecimento autêntico de sua identidade; visto que regularmente são reprimidas dentro de sua própria casa, através da negação da identidade, sendo ela a maior armadilha do racismo. "A realidade humana é resultado da ação de homens concretos, historicamente circunscritos, que só se compõem enquanto tal por intermédio dessa realidade que produzem; isso significa que ao mesmo tempo que o homem faz o mundo tambem é feito por ele" (SILVA; FELÍCIO; ANDRADE, 2018, 01).

Tal artigo visa propiciar uma reflexão sobre a juventude negra de uma região do sudeste do Brasil e algumas questões étnico-raciais. Portanto, as idéias desse estudo irão elucidar as percepções fundamentais no que diz respeito ao sujeito negro, que ocupa um lugar diferente na sociedade em comparação aos brancos, bem como a capacidade perceptiva das relações étnico-raciais que circulam sua história de vida.

\section{METODOLOGIA}

O dado trabalho teve como ferramenta de estudo a metodologia de pesquisa de campo, utilizando a técnica quantitativa. Um questionario foi aplicado com perguntas fechadas de múltiplas opções de escolha para resposta. Os sujeitos envolvidos nessa pesquisa foram jovens negros, de 18 a 29 anos, residentes na cidade de Campos dos Goytacazes, norte do estado do Rio de Janeiro. A pesquisa foi submetido ao Comitê do Ética do ISECENSA e aprovado com o CAAE $\mathrm{n}^{\circ}$ 91546418.7.0000.5524. Os dados coletado foram devidamente tabulados e após analisados pela técnica de análise de conteúdo. Todos os sujeitos da pesquisa assinaram o Termo de Consentimento Livre e Esclarecido.

\section{RESULTADOS E DISCUSSÃO}

No total, 237 participantes foram estudados no município de Campos dos GoytacazesRJ emtre 15 a 24 anos de idade. As características sociodemográficas apresentadas pelos participantes foram: $26 \%$ de jovens entre 19 a 20 anos de idade e $22 \%$ entre 17 a 18 anos; $55 \%$ dos sujeitos da pesquisa foi do sexo masculino; e $48 \%$ com escolaridade de nível superior incompleto.

Madeira e Gomes (2018) fundamentam que apesar da maioria da população brasileira ser negra, a pesquisa realizada pelo IBGE em 2010 aponta que apenas 17,4 milhões de pessoas, $8,6 \%$ dos entrevistados se declararam de cor preta. Também ressaltam que:

o IBGE em seu último senso de 2010 , ressalta que 92,4 milhões de pessoas se
autodeclararam de cor branca representando $45,5 \%$ da população. O grupo de
pessoas de cor parda representava $45 \%$ do total populacional e outros $8,6 \%$ se
declararam de cor preta $(17,4$ milhões de pessoas) e $0,9 \%$ declararam outra cor ou
raça como indígena ou amarela $(1,8$ milhão de pessoas). Para efeitos de políticas
públicas voltadas para a igualdade racial, negros ou afrodescendentes são
considerados os pretos e pardos. É fato que a população negra no Brasil é maioria e
pesam sobre ela opressões, pois convive com as práticas discriminatórias
cotidianamente. O fenômeno da "pardalização" se destaca na autoafirmação da
população e apresenta o pardo como "coringa" para a indefinição (MADEIRA;
GOMES, 2018, p. 469).

Desse modo, o fato da população brasileira ser na sua maioria constituída por indivíduos de cor preta contrapondo com o fato de apenas $8,6 \%$ dos entrevistados pelo IBGE, se declarar negro pode-se perceber que as relações sociais entre os brasileiros são perpassadas

Persp. Online: hum \& sociais aplicada., Campos dos Goytacazes, 26 (9) 98-112- 2019

seer.perspectivasonline.com.br 
pelo racismo, significando que a construção do povo brasileiro é compreendida pelo sentido de superioridade e inferioridade das raçs. Assim, o preconceito racial uma construção de grande impacto na vida dos sujeitos, tendo como base a mesma forma como todos são constituídos (MADEIRA; GOMES, 2018).

Cerca de $42 \%$ dos participantes afirmaram que as pessoas do seu convívio social os consideram negros (as), já 39\% declararam que os consideram morenos (as), 3\% mulatos (as) e marrons (cada) e 2\% escuros (as) (Figura 1). Em contraparte, em torno de $4 \%$ alegam que as pessoas os consideram brancos (as), e aproximadamente $1 \%$ diz que os consideram amarelos (as) e $2 \%$ dizem não saber.

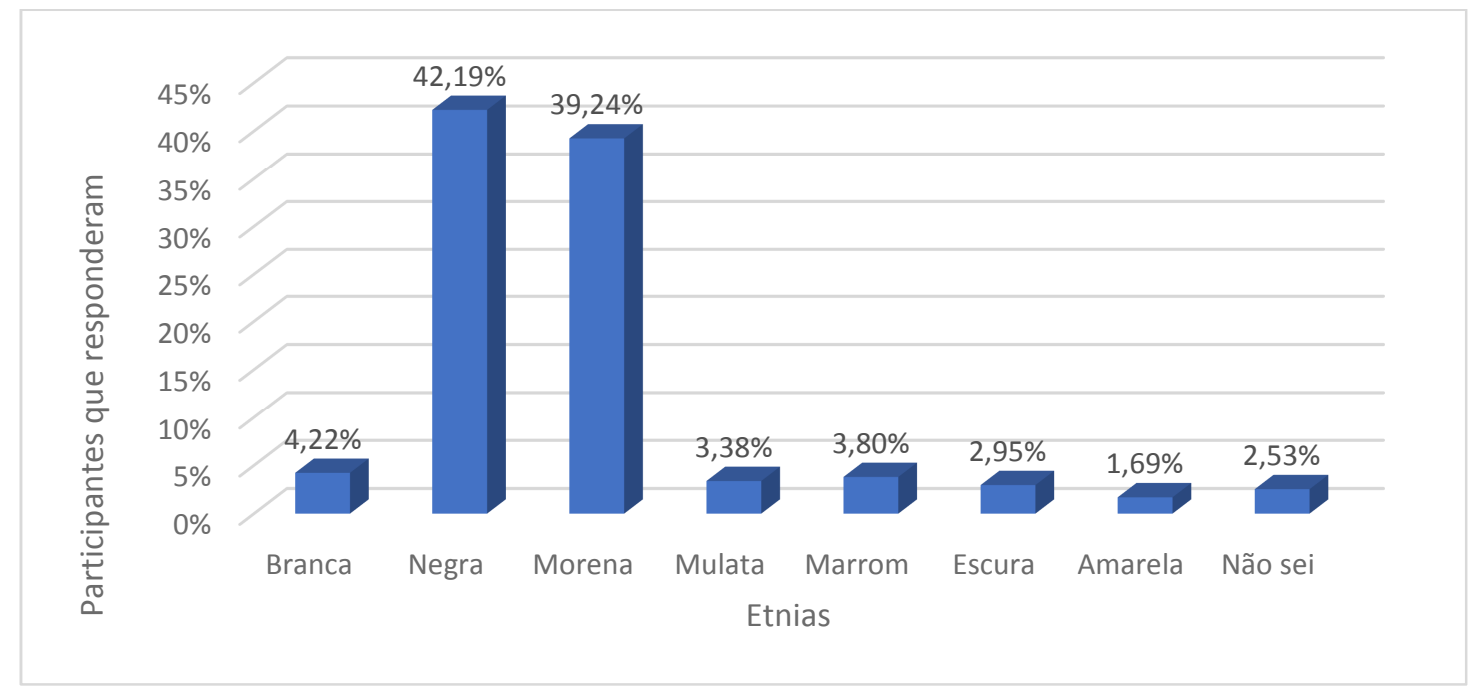

Figura 1: Descrição da etnia por terceiros considerados neste estudo.

Avaliou-se que cerca de $79 \%$ dos participantes nunca foram discriminados por algum de seus familiares, já $20 \%$ afirmam que já sofreram por alguma discriminação no meio familiar (Figura 2).

A família possui papel fundamental na caracterização do ser, visto que a forma pelo qual os indivíduos são identificados e tratados por seus familiares, influencia em todos os outros aspectos e âmbitos de sua vida. "O mundo de significados que atravessa o sujeito, se apresenta em sua vida privada, nas suas relações" (SOBRINHO et al, 2018, p 09).

Com isso, muita vezes, o racismo começa dentro de casa, fazendo com que o sujeito seja ainda mais reprimido, e assim, vai negando suas origens, como por exemplo alisando o cabelo, ou simplesmente se isolando de todo o mundo social, para que não sofra ainda mais as consequências que o racismo traz (RAMOS, 2009). 


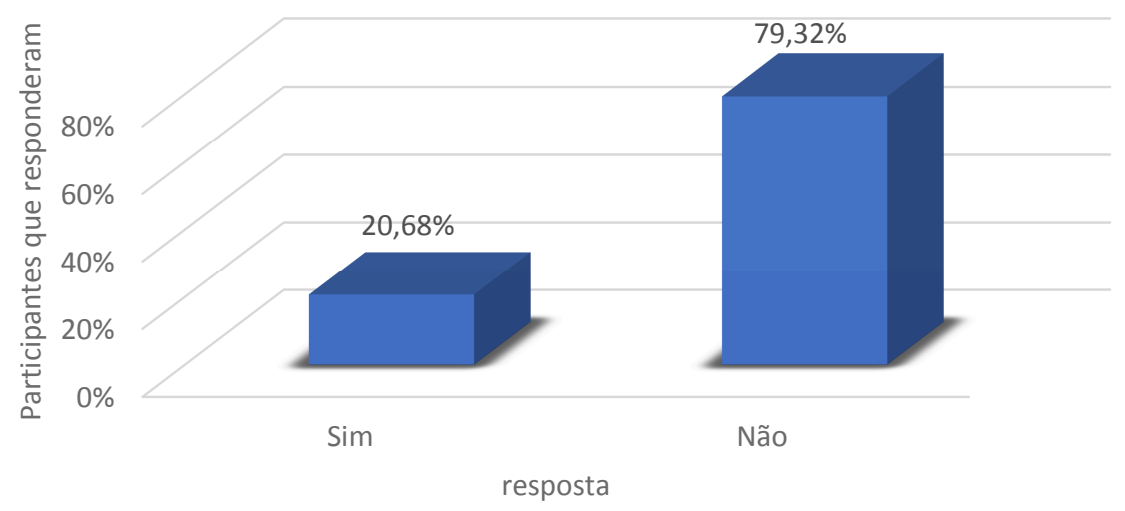

Figura 2: Discriminação dos participantes desse estudo pelos familiares.

Assim, para Gomes e Madeira (2018) a discriminação ocorrida das práticas do racismo institucional nas entidades públicas no Brasil coloca os sujeitos envolvidos em grupos etnicos em um lugar de discriminação, em posição de superioridade ou inferioridade, produzindo maiores direitos sociais de uns em relação a outros.

De acordo com a Figura 3, 30\% dos participantes discordam plenamente com o fato dos afrodescendentes serem representados no cenário político-governamental atual, 12\% discordam parcialmente e $19 \%$ dizem não concordarem e nem discordarem. Em analogia, $15 \%$ concordam parcialmente que os afrodescendentes são representados na política, $6 \%$ concordam plenamente e $14 \%$ dizem não ser nenhuma das opções.

Segundo Nogueira (2017), a falta de representatividade dos afrodescendentes na política se dá pelo fato de sempre o homem branco ser visto como referência e como autoridade na história do Brasil; sendo o afrodescendente, o miserável que não tem nenhuma condição de ser melhor e sobrepor aos ideais dos brancos.

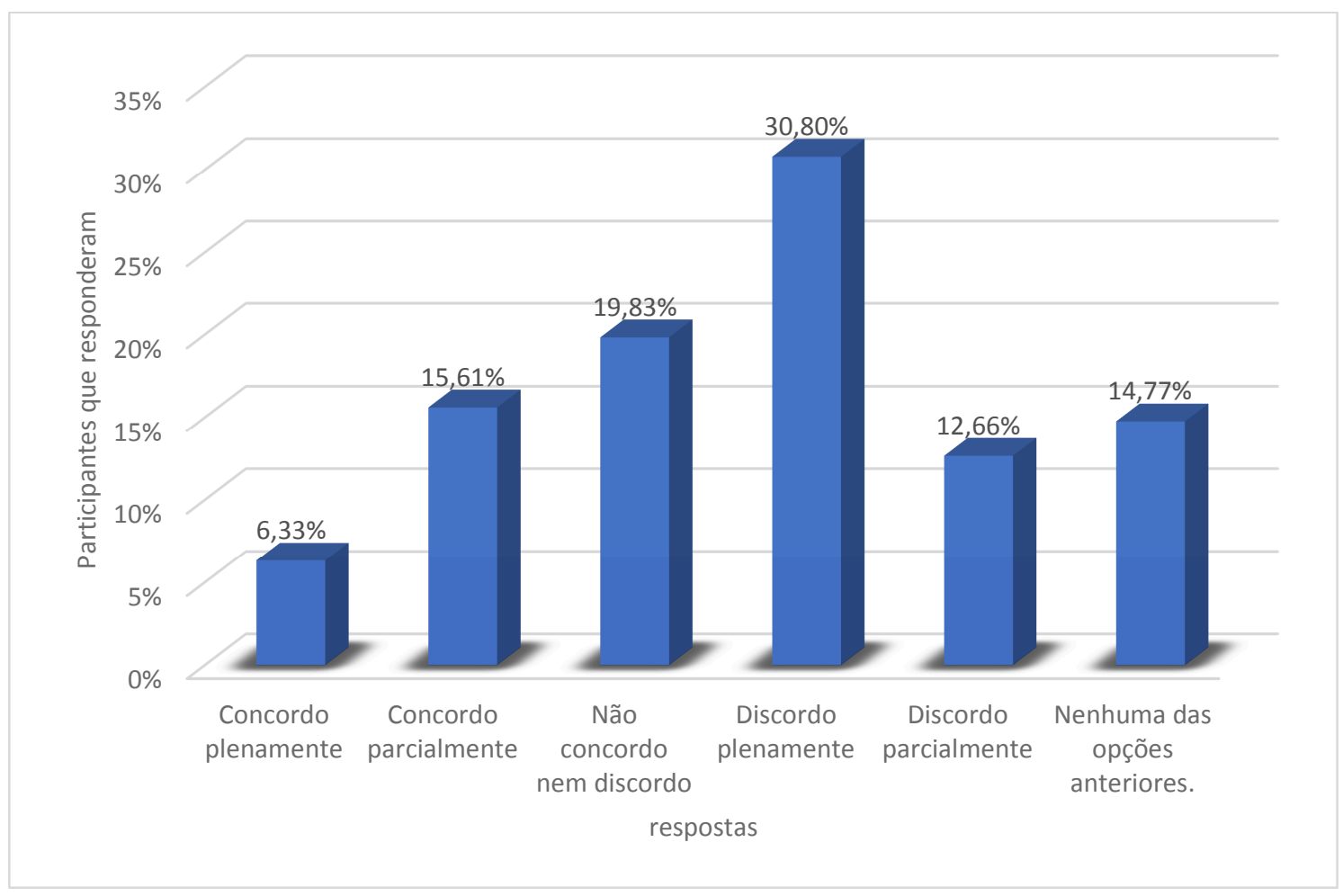

Persp. Online: hum \& sociais aplicada., Campos dos Goytacazes, 26 (9) 98-112- 2019 seer.perspectivasonline.com.br 
Figura 3: Representatividade dos afrodescendentes na política brasileira.

Cerca de $49 \%$ concordam plenamente que as pessoas afrodescendentes têm mais dificuldades de serem inseridas no mercado de trabalho, $28 \%$ concordam parcialmente e $8 \%$ se encontram neutros; já $5 \%$ cada discordam plenamente e parcialmente, além de $2 \%$ não opnarem sobre nenhuma das opções anteriores (Figura 4).

Segundo Silva (2008), a dificuldade dos afrodecendentes no mercado de trabalho é o resultado de uma história que foi criada para o afrodescendente, sendo aquele que é inferior, incapaz, que está sempre a margem quando se diz respeito ao homem branco. De acordo com o Ministério Público do Trabalho (2007), o negro sofre e passa por mais dificuldades na hora de ser empregado, de progredir no seu emprego e ao ter salários melhores, comparados aos brancos.

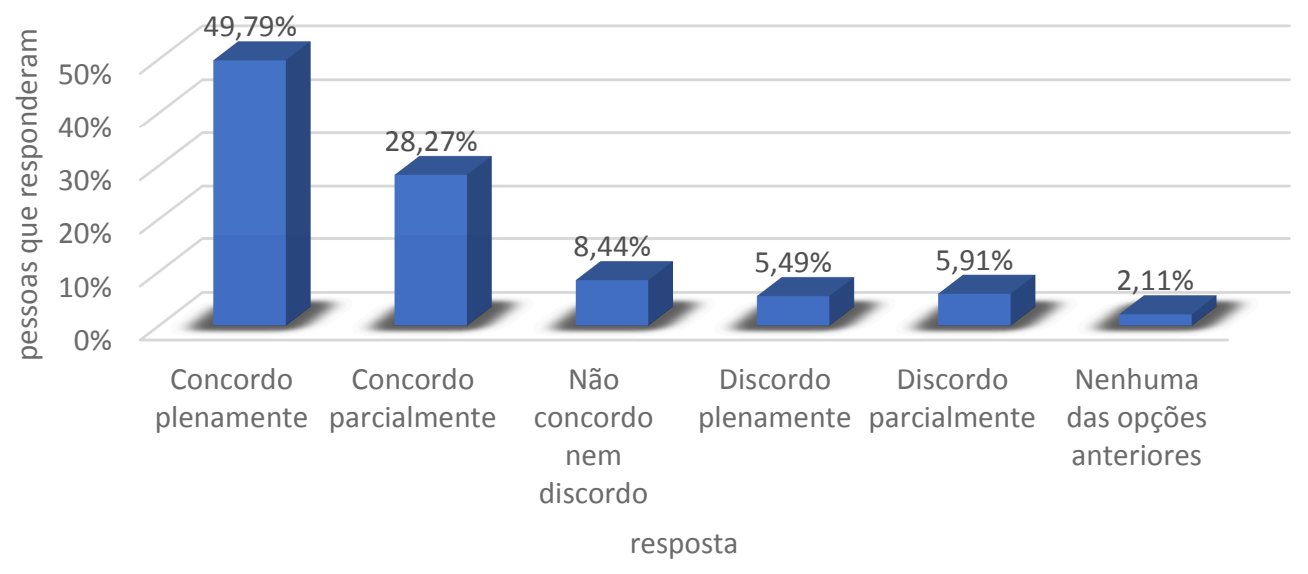

Figura 4: Dificuldade de inserção do afrodescendente no mercado de trabalho.

A Figura 5 mostra que aproximadamente 52\% dos participantes acreditam que há diferença salarial entre pessoas afrodescendentes e brancas que exercem o mesmo cargo e a mesma função, $35 \%$ afirmam que não há diferença e $12 \%$ diz não ser nenhuma das opções.

Segundo o IBGE (2007), os negros recebem cerca de $\mathrm{R} \$ 1,2$ mil a menos do que os brancos no Brasil. Este fato se deve a cultura racista que se instalou na sociedade brasileira, onde o negro tem condições de vida precária e uma qualidade de educação bem inferior comparado ao branco, tais dados são gritantes e não podem ser ignorados. 


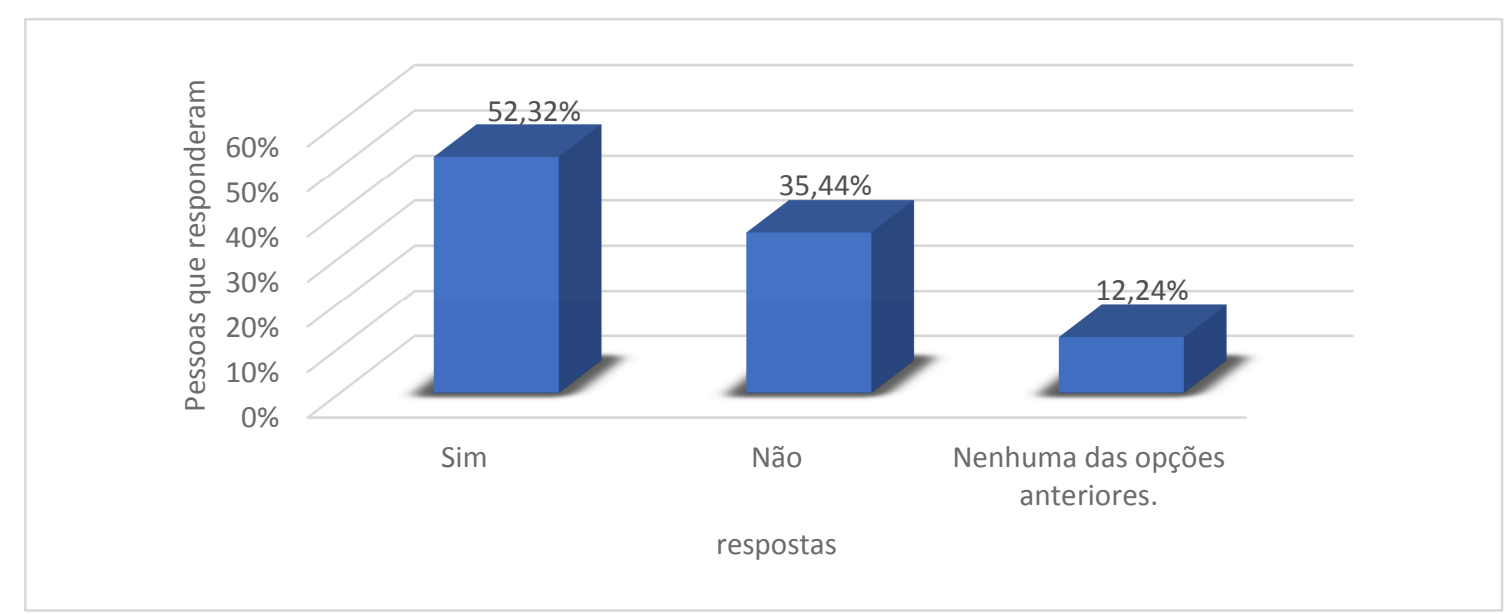

Figura 5: Diferença salarial entre as etnias relatada pelos participantes.

De acordo com a Figura 6, cerca de $56 \%$ dos participantes afirmam que a forma como foi apresentada a história dos negros na escola influenciou em seu pensamento em relação aos mesmos e $43 \%$ dizem que não foram influenciados.

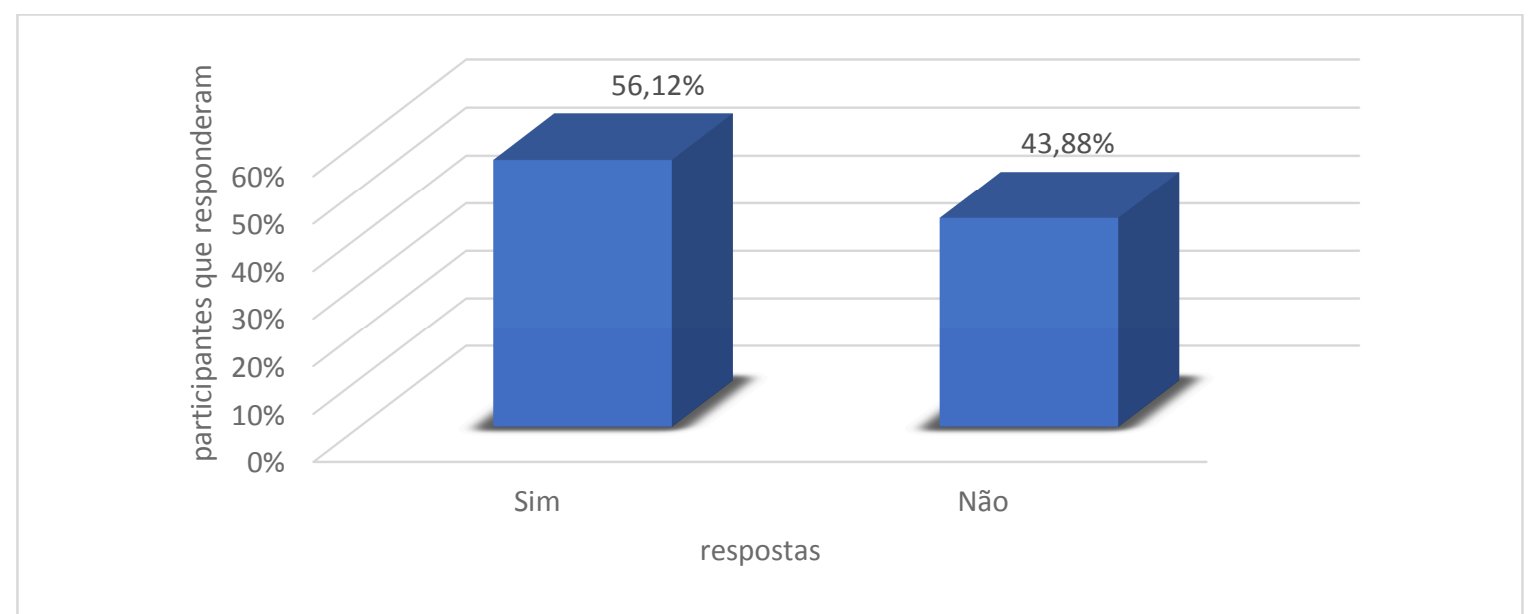

Figura 6: Influência da história do negro contada pela escola na formação do ideal.

Pinto e Ferreira (2014, p. 264) afirmam que a sociedade atual é preconceituosa, visto que pratica a discriminação e atos que caracterizam racismo com frequência, minimizando os diferentes da maioria das pessoas e grupos. Essa perspectiva social do racismo que se tem atualmente é derivada do período escravagista. Este momento histórico da escravatura "foi marcado pela forma animalizada e coisificada como o africano era tratado, uma estratégia que resultou na construção de uma imagem desumanizada do negro" (PINTO; FERREIRA, p. 264) e na desconstrução de sua identidade.

Ademais, pode-se afirmar que a escravidão também contrubuiu fortemente na construção de carcterísticas negativas destinadas ao negro, que ainda permanecem vivas e atuantes no inconciente coletivo (Instituto AMMA Psique e Negritude, 2008). Após a abolição da escravidão houve uma exclusão do negro do mercado de trabalho, ou melhor um não lugar dentro desse processo produtivo, o que favoreceu a formação e reforçamento de estigmas e estereótipos sociais que mantiveram o racismo, como: "incompetentes, preguiçosos, malandros, sujos e marginais” (Instituto AMMA Psique e Negritude, 2008). 
Ribeiro (1996 apud CUNHA, 2015) declara que países da América como o Brasil, teve o seu desenvolvimento caracterizado como nação a partir da chegada dos europeus em suas terras, do genocídio das populações indígenas e implantando o sistema econômico com bases na mão de obra escravocrata da populações africana. Desse modo, Cunha $(2015$, p. 08) afirma que "tais condições históricas favoreceram a presença dos valores africanos nas manifestações culturais brasileiras, que permaneceram preservados ao longo da sucessão de gerações, mostrando-se tacitamente ativos e constituintes do processo de formação da cidadania".

Todavia, Silva e Gossler (2008) destacam que quando o Brasil recebeu o povo africano, não se mensurava nem se imaginava a importância desse grupo e suas contribuições para todos os setores, da cultura, da religião, da economia, das políticas, das artes e tantos outros. Assim, no decorrer do desenvolvimento social, o continente Africano viu-se, com sua enorme variedade cultural, fortemente vinculado à cultura brasileira, pois foram recebidos cerca de cinco milhões de negros africanos no Brasil, com seus costumes, cultura e hábitos, cotribuindo para a formação dessa nação (CUNHA, 2015).

Segundo Pinto e Ferreira (2014, p. 258) “com a abolição da escravatura e o advento do trabalho livre, ocorreram muitas mudanças sociais em que as relações de trabalho se transformaram e o escravo, ao se emancipar, transforma-se em negro livre e assalariado". Desta forma, o negro passou a participar do mundo do trabalho como profissional livre, "vendendo sua força de trabalho de acordo com os ditames da nova ordem competitiva que se instaurava".

Sansone (2004), analisando a juventude brasileira de duas cidades específicas, declarase pessimista quando se trata da edificação de uma identidade negra na America Latina, e particularmente no Brasil. Segundo este autor, a cor da pele não é determinante para se autodeclarar negro, mas sobretudo a idade e até mesmo a sua formação.

Pode-se constatar que ainda há pessoas que atribuem os problemas do Brasil à pobreza, eliminando inteiramente ou parcialmente as discussões a cerca de ser pobre e ser negro e, por outro lado, encontra-se aqueles que constatam a cor como identificação da pobreza (SILVÉRIO, 2004).

Telles (2003) argumenta que a construção do preconceito racial encontrou força e se manteve até os dias atuais por meio dos pensamentos históricos que sustentavem e afirmavam a condição de inferioridade da raça negra em relação a raça branca, vendo os ditos mulatos como uma característica de doença da nação, da raça e da sociedade.

Bobbio; Matteucci; Pasquino (1998) afirmam que a expressão racismo abrange várias dimensões como: o comportamento do sujeito quanto a raça a que pertence, o uso da ferramenta da política com a intenção de demonstranar, por meio de dados aparentemente cintíficos, a superioridade de uma raça em ralação as outras, além da descrição da variedade de raças ou grupos étnicos humanos. Assim, tal expressão acaba também por consentir e justificar ações de exclusão e perseguição contra diferentes raças consideradas inferiores.

Assim, Ramos (2009) argumenta que a exclusão racial como a sua inclusão dentro da sociedade são dados de destaque e relevância, podendo promover a resiliência e o desenvolvimento de muitas e diferentes esferas de identidade racial no meio da juventude afrodescendentes. Em cada momento na história, aconteceu algum tipo de princípio racista, tanto na escravidão, quanto na pós-abolição. Como evento político, a abolição marca o

Persp. Online: hum \& sociais aplicada., Campos dos Goytacazes, 26 (9) 98-112- 2019 seer.perspectivasonline.com.br 
princípio de uma geração onde negro deixa de ser mão de obra escrava e passa a ser livre; o cidadão negro passa a ser visto como indivíduo de segunda classe, isso faz com que a colocação do mesmo seja revista pelos intelectuais e produtores de cultura. A partir disso, que a sociedade é dividida entre: brancos, negros e indígenas. Ressaltnado que os brancos sempre estão ficando em uma colocação maior, dispostos no topo.

Um personagem importante foi Raimundo Nina Rodrigues, um médico brasileiro racista e eugenista, que comentava que as raças superiores se discerniam das inferiores e, que na concorrência social essa raça superior sempre vence (RODRIGUES, 2015). Além disso, o historiador Thomas Skidmore, comenta que a crença do "branqueamento", conduziu os brancos a aceitarem e até mesmo impulsionarem a miscigenação para chegarem a uma sociedade mais branca (RAMOS, 2009).

Schucman et al. (2017) constata que a ausência de distinção biológica entre negro e os não pertencentes a este grupo, não acaba com as desigualdades sociais existentes, ademais a construção estereotipada negativa feita aos negros em detrimento dos brancos com características positivas.

Cabe salientar que Cunha (2015) entende que o preconceito racial e as atitudes em relação a raça negra estão intimamente ligados e que as atitudes racistas são ideias preestabelecidas de inferioridade e desvalor em relação a uma determinada raça, etnia ou povo específico. O preconceito pode ser aferido contra a uma determinada pessoa, bem como pode ser praticado em face de um grupo, porém apresenta sempre algo negativo, ruim, grosseiro, que causa dor e sofrimento àquele que recebe. Assim, o preconceito é oriundo de uma ideia que se formula antecipadamente, sem conhecer a pessoa, onde o julgamento é feito sem conhecimento do que se afirma, sem uma prova consistente.

Bandeira e Batista (2002) apontam que o preconceito é uma maneira autoritária de de se pensar e agir diante do outro diferente, no mesmo momento em que se exerce uma forma de controle social com o intuito de manter claramente, mas de forma sutil e naturalizada, as diferenças e distâncias entre os grupos socias e sujeitos.

Desse modo, preconceito pode ser compreendido como uma ideia preconcebida sobre algo, se manifestando através de atitudes discriminatórias diante de pessoas, credos, cultura, forma de pensar ou agir. Pode-se dizer que o preconceito é hostil e irracional, pois deixa de lado qualquer norma de respeito, humanidade e convivência social em nome da crença de uma superioridade, seja ela física, cultural ou econômica. Essa forma de pensar do preconceito é respaldada muitas vezes pelas representações sociais (CHEMIM, 2013).

Wallerstein (2004) salienta que o preconceito racial está espalhado pelo mundo, pois em nenhum lugar do planeta é possível encontrar uma sociedade livre do racismo, sendo um aspécto característico central das políticas locais, nacionais e mundiais. Contudo, a ação contra o racismo deve demarcar a democracia, visto que o racismo abriu os caminhos para a ocorrência do abismo social entre negros e não negros na sociedade brasileira.

O autor Guimarães (2003) salienta que a raça é uma construção sociológica que faz sentido somente em um contexto histórico e no corpo de uma teoria, uma vez que não é possível definir geneticamente as diferentes raças humanas.

No Brasil, a segregação racial e urbana manteve vantagens materiais e simbólicas aos segmentos sociais brancos. Aos negros, sobretudo aos subproletariados, são destinados os

Persp. Online: hum \& sociais aplicada., Campos dos Goytacazes, 26 (9) 98-112- 2019 seer.perspectivasonline.com.br 
últimos lugares das cidades no Brasil, em condições de precariedade e ausência de infraestrurura urbana (OLIVEIRA, 2017).

Neste sentido, Oliveira e Nascimento (2018) consideram que o racismo, psiquismo e segregação urbana e racial são preteridos pela psicologia, visto que confere complexidade que deve necessariamente implicar a atuação do psicólogo clínico no desvendamento da sociedade brasileira, para compreender os processos de produção subjetiva dos sujeitos negros e brancos nas sociabilidades, nos espaços coletivos e na dimensão individual.

Neste processo, de compreensão e formulação de uma clínica psicológica capaz de sustentar o sofrimento psíquico do racismo e das perversões de um contexto de civilização branca europeia, o psicólogo e profissional de saúde mental precisa compreender que a noção de aparelho psíquico se funda a partir das premissas sociais e inscrição do sujeito no contexto social e coletivo (OLIVEIRA; NASCIMENTO, 2018).

Sendo o racismo uma variante da violência, ele pode ser considerado um forte agentede tormento psíquico para os negros. A psicologia para Schucman et al. (2017), deve assumir uma posição de enfrentamento contra o racismo, visando assim um equilíbrio psíquico desse segmento social. O racismo como uma complicação social, torna-se-a por conseguinte, uma complicação psíquica, assumindo assim um papel psicossocial (SCHUCMAN et al., 2017). Isto posto, a psicologia está frequentemente sendo requisitada e questionada para contribuir no compreendimento das relações entre raças e etnias. Ademais, essa área compreende o desafio de desenvolver ações fecundas para a supereção de desigualdades reciais ainda presentes Brasil (MARTINS; COLOSSO, 2013).

\section{CONCLUSÃO}

Tal estudo se ambasa na luz de pensadores que veem o racismo, o preconceito e toda forma de discriminação como barreiras de integração e construção social, bem como a presença da ciência como fonte de apoio e superação.

O racismo dificulta a comunicação entre os distintos grupos que compõe uma sociedade, pois acaba criando uma barreira resistente, existindo assim, um binarismo de identidade, isto é, uma identidade do que é "ser negro" e uma identidade do que é "ser branco", fundamentados em categorias negativas para o primeiro e positivas para o segundo.

Dessa forma que as relações de racismo consiste em entruturas econômicas e políticas, fazendo com que a raça seja o centro de uma sociedade e uma variável propulsora de exclusão social e produção e reprodução de desigualdades sociais entre o povo negro no Brasil.

A hierarquização do negro é uma tentativa para prendê-lo a uma autoridade adulterada, a um espaço social que exige um cunho de desacreditado. Ou melhor, a "marca" que o negro traz, faz com que os outros não o olhe em sua totalidade, com questões individuais, mas sempre com um olhar denegrido.

Diante do estudo verificou-se a existencia de um grande número de sujeitos negros que se percebem sem oportunidades de se inserirem no mercado de trabalho, sem espectativas de formação educacional e excluídos do cenário social como cidadãos. Neste sentido, essas representações mediadoras das relações étnico-raciais contribuem para reforçar e reproduzir ainda mais o preconceito racial.

Essa pesquisa trouxe esclarescimentos importantes quanto à descrição da etnia por

Persp. Online: hum \& sociais aplicada., Campos dos Goytacazes, 26 (9) 98-112- 2019 seer.perspectivasonline.com.br 
terceiros, à presença ou não da discriminação no meio familiar e à representividade dos afrodescentendes na política. Além disso, este estudo também destacou informações relevantes sobre a dificuldade do afrodescendente para ser inserido no mercado de trabalho, se há uma diferença salarial entre as etnias e por fim, a influência da história do negro contada na escola, como meio de formação.

Conclui-se que, o preconceito racial e as diversas discriminações em torno dessa relação repercutem na comunicação entre os indivíduos, impactando os sujeitos envolvidos, desenvovendo uma dicotomia social entre o negro e o branco de maneira negativa, que vem acompanhado de um adoecimento psíquico, por parte dos negros, fazendo com que uma das partes negue sua identidade.

Através das pesquisas, consultas, indagações e estudos levantados com o teor deste trabalho, cre-se ter dado um passo importante na temática das relações etnico-raciais no território nacional, bem como no município estudado, contribuindo para a fomentação da formação continuada de pensadores e estudiosos no assunto.

\section{REFERÊNCIAS}

BANDEIRA, L.; BATISTA, A.S. Preconceito e Discriminação como expressões de Violência. Revista Estudos Femininos, v. 10, n. 1, 2002.

BARROS, R.P.; MENDONÇA, R.S. Diferenças entre discriminação racial e por gênero e o desenho de políticas anti-discriminatórias. Revista Estudos feministas, v. 1: p. 183-193, 1996.

BOBBIO, N.; MATTEUCCI, N.; PASQUINO, G. Dicionário de Política. 4. ed., Brasília: UnB, 1998.

CHEMIM, M.S.A. O negro no espaço escolar. 2013 Disponível em: http://www.diaadiaeducacao.pr.gov.br/portals/cadernospde/pdebusca/producoes_pde/2013/20 13_uepg_hist_artigo_maria_do_socorro_chemim.pdf. Acesso em: 17 jul. 2019.

CUNHA, M.S. Africanidades: a valorização da cultura negra na escola pode melhorar o relacionamento entre alunos? 2015. Disponível em: http://bdm.unb.br/bitstream /10483/14558/1/2015_MilvaniaSimasdaCunha_tcc.pdf. Acesso em: 15 jul.2019.

Declaração sobre a Raça e os Preconceitos Raciais. Conferência Geral da Organização das Nações Unidas - 20 a . Sessão da Educação, Ciência e Cultura. 1978. Disponível em: http://www.direito.mppr.mp.br/arquivos/File/Igualdade_Racial/1978DeclRaca.pdf. Acesso em: 10 set. 2019.

PINTO, M. C. C.; FERREIRA, R. F. Relações raciais no Brasil e a construção da identidade da pessoa negra. Pesqui. prát. psicossociais, São João del-Rei, v. 9, n. 2, p. 257266, dez. 2014. Disponível em: https://ufsj.edu.br/portal2-repositorio/File/revistalapip /12\%20-\%20Art_\%20712\%20-\%20Pronto(1).pd>. Acesso em: 15 jul. 2019.

GOMES, D. D. O.; MADEIRA, Z. Persistentes desigualdades raciais e resistências negras no Brasil contemporâneo. 2018. Disponível em: http://www.scielo.br/scielo.php?script= sci _arttext\&pid=S0101-66282018000300463. Acesso em: 18 jul. 2019.

Persp. Online: hum \& sociais aplicada., Campos dos Goytacazes, 26 (9) 98-112- 2019 seer.perspectivasonline.com.br 
GUIMARÃES, A.S. Como trabalhar com "raça" em sociologia. Educação e Pesquisa, v. 29, n.1, p. 93-107, 2003.

HASENBALG, C. Discriminação e desigualdades raciais no Brasil. Rio de Janeiro: Graal, 1979. Disponível em: https://pt.scribd.com/document/285951697/HASENBALG-

Discriminacao-e-Desigualdades-Raciais-No-Brasil-Carlos-Hasenbalg. Acesso em: 16 jul. 2019.

INSTITUTO AMMA PSIQUE E NEGRITUDE. Os efeitos psicossociais do racismo. 2008. Disponível em: http://www.ammapsique.org.br/baixe/Os-efeitos-psicossociais-doracismo.pdf. Acesso em: 16 jul. 2019.

MARTINS, E.; COLOSSO, A. Relações étnico-raciais e psicologia: publicações em periódicos da Scielo e Lilacs. Psicologia: Tepria e Prática, v. 15, n. 3, p. 118-133, 2013.

NOGUEIRA, F. Governo Temer como restauração colonialista. Rio de Janeiro: Le Monde Diplomatique Brasil, 2017. p.4-5.

NOGUEIRA, O. Tanto preto quanto branco: estudos de relações raciais. São Paulo: T.A. Queiroz Editor, 1985.

OLIVEIRA, R.M.S.; NASCIMENTO, M.C. Psicologia e Relações Raciais: sobre apagamentos e visibilidades. 2018. Disponível em: http://abpnrevista.org.br/revista /index.php/revistaabpn1/article/view/582. Acesso em: 19 jul. 2019.

OLIVEIRA, R.J. Territorialidade negra e segregação racial na cidade de São Paulo: a luta por cidadania no século XX. São Paulo: Alameda Editorial, 2017.

PINTO, M. C. C.; FERREIRA, R. F. Relações raciais no Brasil e a construção da identidade da pessoa negra. Revista Pesquisas e Práticas Psicossociais, Ed. 9, n. 2, São João del-Rei, julho-dezembro de 2014.

POLIAKOV, L.; DELACAMPAGNE, C.; GIRARD, P. Le racisme. Paris: Ed. Sehers, 1977.

RAMOS, D.G. Formação da identidade e sentimentos de autoestima: um estudo comparativo entre jovens brancos e negros. 2009. Disponível em: http://www4.pucsp.br/jung/download/formacao_autoestima.pdf. Acesso em: 17 jul. 2019.

RIBEIRO, R.I. Alma africana no Brasil. São Paulo: Oduduwa, 1996.

RODRIGUES, M.F. Raça e criminalidade na obra de Nina Rodrigues: Uma história psicossocial dos estudos raciais no Brasil do final do século XIX. Estudos e Pesquisa em Psicologia, v.15, n.3, 2015.

SANSONE, L. Negritude sem etnicidade. Salvador/Rio de Janeiro: Edufba/Pallas, 2004.

SCHUCMAN, L.V.; NUNES, S.S.; COSTA, E.S. A Psicologia da Universidade de São Paulo e as relações raciais: perspectivas emergentes. Psicologia USP, v.28, n.1, p.144-158, 2017

Persp. Online: hum \& sociais aplicada., Campos dos Goytacazes, 26 (9) 98-112- 2019 seer.perspectivasonline.com.br 
SILVA, H.M.R.; GOSSLER, L. A importância do negro na sociedade brasileira. 2008. Disponível em: http://www.administradores.com.br/mobile/artigos/economia-efinancas/ aimportancia-do-negro-na-sociedade-brasileira/26258/. Acesso em: 16 jul. 2019.

SILVA, V. R.; FELÍCIO, C. B.; ANDRADE, E. R. População de rua: possibilidades de um olhar fenomenológico a partir da angústia de Heidegger. Perspectivas Online: Humanas \& Socias Aplicadas, v. 8, n. 22, 2018. Disponível em: https://www.seer.perspectivasonline. com.br/index.php/humanas_sociais_e_aplicadas/article/view/1639. Acesso em: 29 set. 2019.

SILVÉRIO, V.R. Ação afirmativa: percepções da "casa grande" e da "senzala". Revista de Ciências Sociais, v. 26, p. 57-79, 2003.

SILVÉRIO, V.R. O movimento negro e os novos contornos do debate brasileiro sobre raça, etnia e democracia. Anais do XIII do Congresso Luso-Afro-Brasileiro de Ciências Socias, Coimbra, Portugal, 2004.

SOBRINHO, A.G.O. e outros. Estigmatização de pessoas com deficiência visual: como tratar esta questão? Perspectivas Online: Humanas \& Socias Aplicadas, v.8, n.23, p. 1-16, 2018. Disponível em: http://seer.perspectivasonline.com.br/index.php/humanas_sociais _e_aplicadas/article/view/1682/1339. Acesso em: 16 jul. 2019.

SOUZA, M.E.V. Preconceito racial e discriminação no cotidiano escolar. São Paulo: Grupo de Estudos Afro-Brasileiros e Educação, 2005. Disponível em: http://www.anped.org.br/reunioes/26/trabalhos/mariaelenavianasouza.rtf. Acesso em: 14 jul. 2019.

TELLES, E. E. Racismo à brasileira: uma nova perspectiva sociológica. Rio de Janeiro: Relume-Dumará, 2003.

WALLERSTEIN, I. O declínio do poder americano. Rio de Janeiro: Contraponto, 2004. 